\title{
Briginal Communtations.
}

\section{TWO NEW AND USEFUL PREPARATIONS FROM CHLOROFORM: CHLORIC ETHER, AND CHLOROFORM JULEP.}

By Thomas Skinner, M.D., Liverpool; Physician to the Liverpool Dispensaries; Fellow of the Obstetrical Society of London; etc.

[Communicated to the Liverpool Medical Institution, April 3rd, 1862.] There are two physical properties possessed by chloroform which, so far as I am aware, are not alluded to in any of our text books on materia medica; namely-1. Its solubility in alcohol, and subsequent miscibility in water; 2. Its miscibility, if not its solubility, in water.

Lately, while engaged experimenting in order to ascer. tain the probable composition of Davenport's chlorodyne, I accidentally discovered the following valuable facts.

1. If chloroform be dissolved in rectified spirit of wine, of specific gravity 838 , at $60^{\circ} \mathrm{Fahr}$. (L. P.), in the proportion of from one to sixteen minims of chloroform in a fluid-ounce, the resulting liquid is entirely and freely miscible with water in all proportions. On adding minim by minim of chloroform to the measure of thirty or thirty-two minims to the ounce of the mixture, the solution ceases to be miscible with water in any proportion; the chloroform spontaneously precipitating in small globules, which ultimately coalesce.

2. If chloroform be added to distilled or any good drinking water, in the proportion of half a fluid-drachm to a pint (twenty fluid-ounces), and briskly agitated, the resulting liquid is perfectly clear and bright, and no globules of chloroform are precipitated, nor can any be detected with the microscope by a power equal to 250 diameters. On adding more chloroform gradatim, the point of saturation is not arrived at until the proportions are a fluid-drachm to a pint of water. Sixty-four minims to the pint render the mixture quite opalescent, and much of the chloroform is precipitated. At the point of saturation, a drop of any essential oil shaken with the mixture will determine the separation of the chloro. form. If the whole fluid-drachm of chloroform be added at once to a pint of water, and shaken, the result. ing iiquid will not be so clear as when it is added gradually.

Bearing these interesting facts in mind, I resolved to put them to some practical use; and I beg to suggest the propriety of there being two new officinal preparations of chloroform, the names and formula for which shall be as follow :-

Spiritus Formyli Terchloridi (commonly called chloric ether):-Chloroform, $3 \mathrm{v}$; rectified spirit of wine, sp. gr. .838 (L. P.), Oj. Mix. Dose, jss to $3 \mathrm{ij}$.

Mistura Formyli Terchloridi (or chloroform julep):Chloroform, $\overline{5}$ ss; pure water, ()j. Mix thoroughly with brisk agitation, for a minute or two, in a vessel capable of containing double the quantity. Dose, ऊis to $\mathrm{ij}_{\text {. }}$

Either preparation may be prepared from the methylated chloroform; but hitherto I have preferred the unmethylated for administration by the prima via.

A chemical nomenclature has been chosen, in deference to the possible and not improbable fears of the patient.

Remarks. The first preparation requires little to be said about it beyond this : that, although it is already very well known to medical men, and to both wholesale and retail druggists, yet, strange to say, its actual com. position and the method of preparing it have been kept a secret from the profession, and from the members of the drug-trade as a body. I have been informed that Professor Neligan gives a formula for chloric ether, and that there is one wholesale house in London that makes it according to his formula. I can only say that the house alluded to must sell chloroform for chloric ether, as Dr. Neligan's formula is for chloroform, which at one time passed under the cognomen of chloric ether-a less questionable title than that given to the solution of chloroform in spirit of the present day. (See Neligan on Medicines, 2nd ed., 1847, p. 257; and subsequent editions-1851, for instance, p. 301.)

In this town alone there are not two preparations of the so-called chloric ether alike, either in composition or in the invaluable property of being miscible in water. In the April number of the Pharmaceutical Journal, Mr. Norman Tate, of this town, has shown that, out of thirteen specimens of chloric ether obtained by him from various druggists in Liverpool and Birkenhead, there is a difference of $9 \frac{1}{2}$ per cent. between the strongest and the weakest samples. As regards the formula for chloric ether above given, I can aver, from considerable clinical experience, that if it be prepared from bona fide materials, it will equal in medicinal virtue the best chloric ether in the market.

With reference to the other preparation, the chloroform julep, I believe it has hitherto been quite unknown; but the simplicity of its composition, the pleasantness of its taste, the fragrance of its odour, its great and undeniable power as a diffusible stimulant, and its capabilities as a safe and excellent vehicle for adminis. tering other remedies, alkaline, acid, or neutral, bitter, sour, or foetid, need only be alluded to in order to insure it a ready acceptance by the practitioner of medicine. This preparation is reported by some who have tried it to be reckoned a specific for toothache and other painful affections of the mouth and gums. It is simply used as a lotion, wash, or gargle.

The strengths of the foregoing preparations have been made considerably below their respective points of saturation, partly in order to render the dose less irritating to the mouth and throat, and partly to prevent the separation of the chloroform on the addition of an essential oil or such like medicine to a mixture, particularly if prepared from the julep.

In conclusion, whether the above formulæ ever become officinal or not, it is to be hoped that a fixed standard will be given to the spirit of chloroform and chloroform julep in the first or second edition of the coming National Pharmacopæia.

\section{RARE CASES IN MIDWIFERY.}

By Edward Copedran, M.D., Physician to the Norfolk and Norwich Hospital.

[Continued from page 40\%.]

Case xr. Dismemberment. Mrs. W., aged 25, a poor woman residing in Lakenham, supposed to be between seven and ejght months gone in pregnancy, met with some accident on May 28th, 1859, which was soon followed by labour-pains and the escape of liquor amnii. On the following day, however, she was free from pain, and all symptoms of labour passed off. On Monday, the 30th, she again felt pains, but they left her in the evening, and she was able to walk into the town. On Tuesday, she again had slight labour-pains, which left her in the middle of the day, and returned at night; when, finding herself gradually getting worse, she sent for the midwife who had been engaged to attend her. The pains were not very severe, and for some time I understand the midwife was unable to feel the presentation; but at some period of Wednesday morning, June 1st, she dis. covered either a foot or a hand. It proved to be the 459 
latter; and, after a while, the arm occupied the vagina, and the shoulder was forced into the inlet of the pelvis. About noon, Mr. — was called in; and, after making some ineffectual attempts to turn the child, he requested the attendance of $\mathrm{Dr}$. — He, also, endeavoured to turn the child, but without success; and at about 5 P.s., I was summoned to their assistance. On my arrival, I found the right hand protruding externally, the shoulder grasped firmly by the uterus and filling the inlet of the pelvis, the vagina by no means capacions, and the soft parts dry instead of being lubricated by the natural secretion. A small coil of the umbilical cord was also to be felt. The patient had a good puise; there were scarcely any labour-pains; but she was getting weary, and suffered a good deal from the necessary manipuiations. This was her second labour, and her first had been very severe. The position of the child was as follows :- the right arm in the vagina, the child's back to the back of the mother, the occiput lying in front and above the pubes, the chest and abdomen of the child towards the abdomen of the mother. I endeavoured to turn, but with no better success than those who had preceded me, not being able to introduce my fingers more than half their length into the uterus. I first tried with my left hand in the direction of the left sacroischiatic notch, and kept my hand in the position above described an hour, in the hope that I should be able by continued pressure to dilate the inordinately unyielding uterus, but even then could get no further into it. We then gave chloroform, and I made an attempt to introduce my right hand in the situation of the right aceta. bulum; but, after passing it quite into the vagina, I could get my fingers only about half their length between the firmly contracted rim of the uterus and the left shoulder of the child, although I kept them there more than hour, trying, with such a degree of pressure as I dared to use, to produce dilatation; until, indeed, I had lost all sense of touch, and could not in the least distinguish one part from another. The uterus, even under chloroform, would not give way in the least, and the inlet of the pelvis also appeared to offer considerable obstruction. After this, Mr. Master came to us, and, after another administration of chloroform, tried to turn, but with no better success than the rest. By this time, it became a matter of certainty that version was an impossibility, and that other means must be devised in order to save the woman's life. She had still a firm pulse, and we gave her several doses of antimonial wine, with the view of relaxing the uterus; but even after free vomiting there was no difference in this respect.

It was now about 9 P.M., and as the patient wanted rest and nourishment, we agreed to wait two hours, and then determine what further course to pursue. At 11.30 , we met again, and finding things in precisely the same condition, I proceeded to deliver in the following manner.

After relieving the bladder by the catheter, I passed my vectis over the left shoulder of the child, so that by this means, and traction upon the protruding right arm, I might bring the right shoulder as much within reach as possible. I then withdrew the vectis; and, by pulling down the arm with my left hand, I was enabled to reach the scapula with my right fore-finger, with which $I$ made way through the skin between the scapula and ribs, and separated the whole upper extremity from the body of the child. Having thus removed the right upper limb, I was enabled by a little careful manipulation to pass a blunt hook over the left humerus, which I brought down, and then removed the arm and scapula in the same way as the other. I then with ny fingers broke into the right side of the chest, and removed nearly all the ribs of that side; and then, by getting my fingers round the bodies of the vertebræ, I bent the back to an angle, and by a kind of manipulation not easy to describe, effected the evolution of the child so as to deliver it by the breech; the rest was compa- $c$ ratively plain sailing, although the head offered some difficulty. The placenta followed immediately without hamorrhage, and the uterus remained firmly contracted.

Thus ended the most difficult operation I ever was $\frac{\bar{\sigma}}{\bar{c}}$ called upon to perform; and whether considered with $\frac{\bar{\omega}}{\sigma}$ reference to the prolonged and diffieult manipulation $\mathbb{\Phi}$ required; the harassing shrieks and movements of the patient, increased as they were by chloroform; or the $\infty$ consternation produced in the neighbourhood, the inha. $\overrightarrow{0}$ bitants of the houses in the street being collected in ? groups ontside their doors; it was, without exception, $\overrightarrow{\overrightarrow{\vec{J}}}$ one of the most trying scenes I ever witnessed, and $\vec{\omega}$ such as I hope never to witness again. The bright $\frac{O}{\partial}$ point about it is, that the poor woman, a few days after- $\frac{0}{3}$ wards, was going on as well as if the labour had been of the most ordinary kind; and she recovered without any $\overrightarrow{-}$ further difficulty.

The case is full of practical interest; and the follow. ing facts are worthy of notice amongst others; viz., the persistent rigidity of the uterus even under chloroform; and the posisibility of accomplishing the dismemberment of the child with no other instrument than the fingers. The child had been dead some hours before delivery.

CASE XII. Occlusion of the Vagina,' with subsequent Premature Dclivery and Death. A. B., a young woman, aged about 27 , and not of strong constitution, was confined with her first child between two and three years ago; the child was full grown and healthy, and born $N$ alive after a somewhat difficult labour, in which forceps were used. She had a protracted recovery. The soft parts were much inflamed and swollen, and there was considerable purulent discharge. After some weeks, however, all this subsided; but she found, although she was well in other respects, her urine was always escaping involuntarily, rendering her life a burden to her; and at this period I was requested to visit her. On examination, I found the vagina occluded, forming a very shallow cul-de-sac, at the apex of which in front there was an opening through which the forefinger readily passed into the bladder; but nowhere could I find any opening leading into the vagina through the septum; although, as she some time afterwards menstruated, there must have been a small opening which, after several careful examinations, I could not dis. cover. Subsequently she went to London, and became a patient of Mr. I. B. Brown, who operated upon the vesico-vaginal fistula with perfect success, although nothing was done to reopen the vagina. Some time after her recovery from this operation, which, let me say, reflected great credit upon the operator, she presented herself to me again for examination, and the $N$ following was the condition in which I found her. The vesico-vaginal opening was entireiy closed, and she had regained considerable power over the bladder; although when standing long at a time, some urine would escape $N$ involuntarily, perhaps owing to the shortness of the urethra. The vagina was quite occluded by a septum of $\omega$ considerable thickness situated just within the ostium vaginæ; at least, no opening could be discovered even by a probe. But as she was able to menstruate, I told her that in all probability she might be impregnated if $\mathbb{E}$ she incurred the risk; and in that case she could not be delivered without an operation that might put her life in danger. This caution, however, was without effect; and in the latter part of last year she called to tell me she feared she was pregnant, and more than two months gone. I examined her again, and believed her statement to be correct; but the only difference in the state of the parts was that the vagina was a little elongated posteriorly, no doubt from attempts at copulation.

In January of the present year (1862), I was requested to see her, as she had been in pain and was lusing

\section{,}


blood. I visited her in conjunction with two other medical men; she had had uterine contractions for a day or two at intervals, and had lost upon the whole a large quantity of blood. She was depressed in spirits; anxious in countenance; her pulse was hurried and feeble; nothing could be satisfactorily made out by vaginal examination; we believed it to be a case fraught with unusual difficulty, and advised her removal to the Norfolk and Norwich Hospital, where she could be ensured the most careful attention, and the combined advice and assistance of the whole medical staff, if required. Before removal, she had a shivering fit, followed by fever; but was taken to the hospital on the evening of January $8 \mathrm{th}$, and had a quiet night. Next morning, she had return of pain and flooding; and as it was evident that labour had commenced in earnest, it was thought right in the after. noon to take steps to facilitate delivery. Chloroform was administered; and on carefully examining the vagina with a large speculum introduced as far as it would go (little more than an inch), a small spot was discovered on the stretched septum, through which clotted blood kept escaping, but it was not large enough to admit a director without difficulty. It was cleur, however, that it was through this very small opening that she had botli menstruated and been impregnated; and as the uterus could be felt, by the finger passed into the rectum, at some distance behind the septum, it was determined to enlarge this opening with a bistoury, and trust to what might then be discovered. This being done to the extent of admitting a finger freely, a large quantity of clotted blood escaped from the vagina, which formed a large pouch between the septum in front and the uterus behind, having been greatly distended by the blood which had been escaping for a day or two from the uterus. The cause of the hæmorrhage was found, to our dismay, to be a placenta prævia, a portion of which had become detached and projected through the os. The opening in the septum was again enlarged so as to admit two fingers, and attempts were made to separate the rest of the placenta. A large portion of it was removed, and then a fresh difficulty presented itself; the presentation was an arm, which, with a portion of the cord, escaped into the vagina. The operation occupied a long time, the patient had been long enough under chloroform; she now began to vomit, had a rapid indistinct pulse, and seemed in a very precarious state. Loss was still going on to a greater extent thun she could bear, and as nothing but delivery could give her a chance the opening was dilated so as to gradually admit the hand, and a dead fotus of about five or six months was soon extracted. Some of the placenta, however, still, it was thought, remained attached to the uterine walls, but the condition of the poor woman was such as to preclude any further interference except with the view to support her and endeavour to keep her alive. But, alas! she was too far gone; what with previous mental apprehension, loss of blood, pain, chloroform, and a prolonged and difficult operation, she became deally faint; it was impossible to keep her warm, she called out madly for cold water and fresh air, nothing would keep upon her stomach, she tossed and rolled about the bed; and after two or three hours, death closed the horrid scene. What a frightful complication of difficulties! 'The operation required for opening the vagina sutficiently to allow a fœtus to pass is of itself attended with risk, and sometimes with loss of life; but when, in addition to this, there is placenta previa accompanied with hæmorrhage, and arm presentation with no access to the uterus except through an artificial opening, truly it is scarcely possible to imagine a more untoward train of circumstances, and scarcely reasonable to expect any other than an unfavourable and fatal result.

[To be continued.]

\section{胥e}

Another Letrer to a Young Physician: to which are appended some other Medical Papers. By James Jacks $:$, M.D., Professor Emeritus of the Theory and Practice of Medicine in Harvard University. Pp. 179. Boston: 1861.

Dr. JAckson belongs to a class of men in the profession of which we see scarcely enough; that is to say, men who have passed a long life in practice, and at the close of it communicate the results of their observation and experience to their younger brethren. The author of this letter dates the commencement of his active career as a practitioner from October 1800, more than sixty-one years ago. Three or four years since, he published a volume of Letters, which were noticed in this Journal, and which shewed him to be a man who, having taken notice of the advaices made in medical science, recognised their value, and was desirous of contributing his share of information, in his own way, to the general stock of knowledge. In the present letter, Dr. Jackson comes forward to express his opinions on a subject which has in late years been much agitated in the medical world-the Utility of Medicines.

His medical creed is that of an empiricist. $\mathrm{He}$ does not believe that the time has yet come for the foundation of a system of rational medicine; although we of the present time are better prepared for the foundation of a satisfactory system of medicine than any of our predecessors.

"Before we can make a system of rational medicine, our stock of knowledge must be increased in each and all of the various departments of our science. First, our physiology must be perfected in its details; in regard to the elements of the human body, its structure, the powers belonging to its various parts, the functions performed by each of these parts, etc. Secondly, we must understand how, or in what mode foreign agents act on the living body; in what way they do good, and in what way they do harm. We should be able to ascertain when such agents modify the functions only, and when they lead to or induce changes in the structure of the part they act on. We must be able to ascertain whether there are any natural processes, by which disease is removed; and, if so, in what cases this happens, and in what it does not; and when there are not any such natural processes, we should be able to point out modes of obviating the evils of the disease, the remedies which nature has furnished for this purpose, and their modus operandi." (1.6.)

Dr. Jackson points out that, in the absence of this knowledge, and in the desire to form a system of medicine, systems have been devised and adopted; but not one of them has stood its ground in trial. And, indeed, the souridest practitioners have never bound themselves to systems, but have been guided by their own experience-and this, in the author's opinion, must be the case, until a system of medicine shall be founded on a rational and unassailable basis. Our practice, then, according to Dr. Jackson, must for the present be empirical-founded on experience.

As a commentary on these opinions of an old practitioner, who, while he holds by the old lights, does not (as he has said in his former Letters) despise

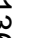

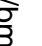

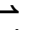
$\longrightarrow$ 